\title{
Systemic allergic dermatitis caused by sodium metabisulfite in rectal enemas
}

\author{
Ana S. Borges ${ }^{1}\left(\mathbb{D}\right.$, Margarida M. Valejo Coelho ${ }^{1}$, Cândida Fernandes ${ }^{1}$, Ana Brasileiro ${ }^{1}$ \\ and Margarida Gonçalo ${ }^{2}$ (D)
}

${ }_{1}^{1}$ Dermatology and Venereology Department, Hospital Santo António dos Capuchos, Centro Hospitalar de Lisboa Central, $1169-050$ Lisbon, Portugal and ${ }^{2}$ Clinic of Dermatology, University Hospital and Faculty of Medicine, University of Coimbra, 3000-075 Coimbra, Portugal

doi:10.1111/cod.12971

Key words: case report; rectal enemas; sodium metabisulfite; systemic allergic dermatitis.

Sulfites are widely used as preservatives and antioxidants in food and beverages, but also in cosmetic and pharmaceutical products (1) and medical devices (2). Allergic contact dermatitis caused by sodium metabisulfite has been increasingly recognized in recent years, and positive patch test reactions seem to be relevant in most patients if carefully investigated $(3,4)$. Furthermore, systemic allergic reactions to sulfites have also been described following oral and/or parenteral exposure (5-7).

\section{Case Report}

A 58-year-old man suffering from ulcerative colitis treated with oral mesalazine (5-aminosalicylic acid) $3 \mathrm{~g}$ for 4 years without significant side-effects presented with recurrent pruritic erythematous lesions located bilaterally on the inguinal area for 3 months soon after Salofalk ${ }^{\circledR}$ and Pentasa ${ }^{\circledR}$ enemas had been added to the treatment (Fig. 1a,b). Lesions developed initially 2 days after the use of a Salofalk ${ }^{\circledR}$ enema. Therefore, the patient was switched to a Pentasa ${ }^{\circledR}$ enema, which, however, provoked a recurrence of the lesions. These diminished only after 3 days of treatment with oral steroids. The patient denied application of topical products to that area and the use of any other systemic drug. He also mentioned previous episodes of a transient rash 2 days after drinking wine. Apart from ulcerative colitis, his medical history included asthma controlled with montelukast and bronchodilators, and eosinophilic gastritis with histopathological confirmation 1 year previously, for which he was treated with esomeprazole.

Correspondence: Ana S. Ribeiro Borges, Dermatology as Venerology Department Hospital Santo Antonio dos Capuchos, Centro Hospitalar Lisboa Central, Lisboa, Portugal. Tel: +351 213136300; Fax: +351 213562208; Email: a.sofia.r.borges@gmail.com

Conflict of interest: There are no conflicts of interest to be declared.

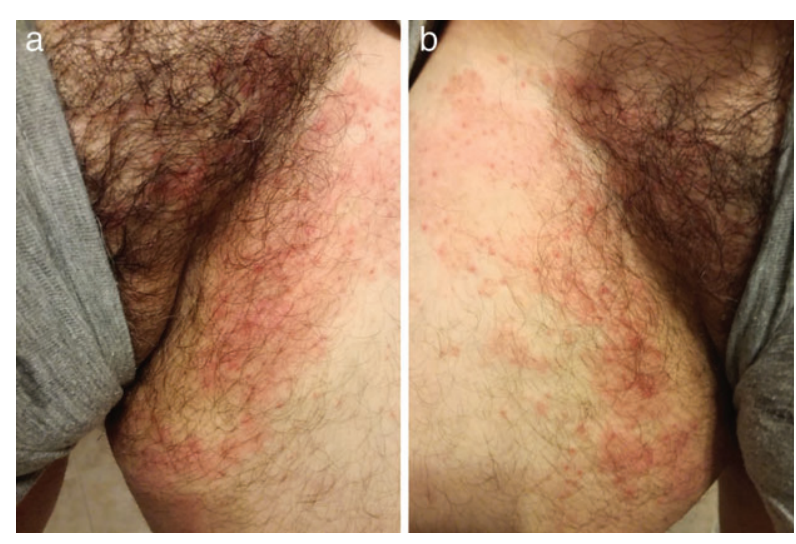

Fig. 1. Symmetrical confluent maculopapular lesionslocalized in the inguinal area and upper thighs.

On examination, the patient had symmetrical confluent maculopapular lesions with ill-defined borders, with some lesions resembling erythema multiforme, localized in the inguinal area and on the upper thighs. There was no involvement of the buttocks or perianal area.

Contact dermatitis was suspected, and patch testing was performed with the Portuguese baseline series, the patient's own enemas, that is, Salofalk ${ }^{\circledR}$ 'as is' (containing mesalazine, sodium benzoate, disodium EDTA, sodium metabisulfite, potassium acetate, and xanthan gum) and Pentasa $^{\circledR}$ 'as is' (containing mesalazine, disodium EDTA, sodium metabisulfite, sodium acetate, and hydrochloric acid), and relevant excipients. Readings on day (D) 3 and D7 showed positive reactions to Salofalk ${ }^{\circledR}(++,++)$, Pentasa ${ }^{\circledR}(++,++)$, and sodium metabisulfite $1 \%$ pet. (Chemotechnique, Vellinge, Sweden;,++++ ). Patch tests with Salofalk ${ }^{\circledR}$ and Pentasa ${ }^{\circledR}$ enemas 'as is' in 10 healthy volunteers gave negative results. 
The patient was advised to avoid sulfites in the diet, and stopped using enemas. No relapse of cutaneous lesions was noticed during 6 months of follow-up, although therapy with oral mesalazine was maintained.

\section{Discussion}

In this patient, positive patch test reactions to sodium metabisulfite and the enemas containing this antioxidant, the occurrence of a bilateral inguinal eczematous rash following the use of enemas, clearing on withdrawal, good tolerance to oral mesalazine and the absence of other possible culprits supports the diagnosis of systemic allergic dermatitis caused by sodium metabisulfite present in the enemas.

Systemic allergic dermatitis is an under-recognized condition with variable clinical presentations. It occurs when an individual sensitized to a contact allergen is exposed to the same allergen or a cross-reacting molecule through a systemic route (8). Rectal application of an allergen (usually a drug) is an important route for systemic absorption, so it has to be considered in cases of systemic allergic dermatitis (9).

To the best of our knowledge, this is the first case of systemic allergic dermatitis caused by sulfites present in enemas for the treatment of ulcerative colitis. The rectal mucosa already being an important area for systemic absorption, the damaged barrier of the gut resulting from the inflammatory bowel disease may have even facilitated transmucosal exposure. Therefore, this case highlights the importance of considering systemic allergic dermatitis in atypical clinical presentations, as well as the role of sulfites in such clinical pictures.

\section{References}

1 Madan V, Walker S L, Beck M H et al. Sodium metabisulfite allergy is common but is it relevant? Contact Dermatitis 2007: 57: 173-176.

2 Grosch E, Mahler V. Allergic contact dermatitis caused by a catheter system containing sodium metabisulfite. Contact Dermatitis 2017: 76: 186-187.

3 Ralph N, Verma S, Merry S et al. What is the relevance of contact allergy to sodium metabisulfite and which concentration of the allergen should we use? Dermatitis 2015: 26: 162-165.
4 Riemersma W A, Schuttelaar M L, Coenraads P J. Type IV hypersensitivity to sodium metabisulfite in local anaesthetic. Contact Dermatitis 2004: 51: 148.

5 García-Gavín J, Parente J, Goossens A. Allergic contact dermatitis caused by sodium metabisulfite: a challenging allergen: a case series and literature review. Contact Dermatitis 2012: 67: 260-269.

6 Barbaud A. Place of excipients in systemic drug allergy. Immunol Allergy Clin North Am 2014: 34: 671-679.
7 Cussans A, McFadden J, Ostlere L. Systemic sodium metabisulfite allergy. Contact Dermatitis 2015: 73: 316-317.

8 Winnicki M, Shear N H. A systematic approach to systemic contact dermatitis and symmetric drug-related intertriginous and flexural exanthema (SDRIFE): a closer look at these conditions and an approach to intertriginous eruptions. Am J Clin Dermatol 2011: 12: 171-180.

9 Marques C, Faria E, Machado A et al. Allergic contact dermatitis and systemic contact dermatitis from cinchocaine. Contact Dermatitis 1995: 33: 443. 